\title{
Motion Discrimination and the Motion Aftereffect in Mouse Vision
}

\author{
[D Jason M. Samonds, ${ }^{1,2,3}$ Sarina Lieberman, ${ }^{1}$ and Nicholas J. Priebe ${ }^{1,2,3}$
}

https://doi.org/10.1523/ENEURO.0065-18.2018

${ }^{1}$ Department of Neuroscience, ${ }^{2}$ Center for Perceptual Systems, and ${ }^{3}$ Center for Learning and Memory, University of Texas at Austin, Austin, Texas 78712

\begin{abstract}
Prolonged exposure to motion in one direction often leads to the illusion of motion in the opposite direction for stationary objects. This motion aftereffect likely arises across several visual areas from adaptive changes in the balance of activity and competitive interactions. We examined whether or not the mouse was susceptible to this same illusion to determine whether it would be a suitable model for learning about the neural representation of the motion aftereffect. Under a classical conditioning paradigm, mice learned to lick when presented with motion in one direction and not the opposite direction. When the mice were adapted to motion preceding this test, their lick behavior for zero coherence motion was biased for motion in the opposite direction of the adapting stimulus. Overall, lick count versus motion coherence shifted in the opposite direction of the adapting stimulus. This suggests that although the mouse has a simpler visual system compared with primates, it still is subject to the motion aftereffect and may elucidate the underlying circuitry.
\end{abstract}

Key words: classical conditioning; motion aftereffect; motion coherence; mouse; vision

\section{Significance Statement}

The motion aftereffect is a well-known illusion that provides insight about motion processing and adaptation throughout the visual system. We demonstrate that motion discrimination in mice is affected by extended viewing of coherent motion, in a manner consistent with the effects reported in primates. The mouse model currently offers unprecedented experimental tools for studying neural circuitry and our results support the mouse as a model to study this phenomenon.

\section{Introduction}

Prolonged exposure to sensory stimuli induces systematic changes in the way that we perceive the world. One such change in our perception is the "waterfall" illusion, in which we perceive motion of stationary objects right after observing moving objects for an extended period. This perceived motion is in the opposite direction of the moving objects. Observing the downward movement of a

Received February 9, 2018; accepted November 15, 2018; First published December 12, 2018.

The authors declare no competing financial interests.

Author contributions: J.M.S. and N.J.P. designed research; J.M.S. and S.L. performed research; J.M.S. and S.L. analyzed data; J.M.S. and N.J.P. wrote the paper.

This work was supported by National Health Institutes Grants U01NS094330, EY025102, and a Human Frontier Science Program Grant. We thank Allison Laudano, Chris Lee, Veronica Choi, Cornelius Schwarz, and Devon Greer for technical assistance, and Alex Huk and Thad Czuba for helpful discussions. waterfall causes surrounding stationary objects to appear as if they are moving upward (Addams, 1834). The neural basis of this motion aftereffect has been elusive but is thought to reflect imbalance and competition in the responses of motion-selective neurons in multiple visual areas (Anstis et al., 1998).

To explore the neural circuitry underlying the motion aftereffect, we sought to develop a motion discrimination paradigm in mice, because there is an array of transgenic

Correspondence should be addressed to Dr. Jason M. Samonds, University of Texas at Austin, Austin, TX 78712. E-mail: samondjm@gmail.com. https://doi.org/10.1523/ENEURO.0065-18.2018

Copyright (C) 2018 Samonds et al.

This is an open-access article distributed under the terms of the Creative Commons Attribution 4.0 International license, which permits unrestricted use, distribution and reproduction in any medium provided that the original work is properly attributed. 
mice that would allow us to manipulate and measure individual circuit elements. Early attempts to train mice to perform motion discrimination of opposite directions were not successful (Douglas et al., 2006) though, suggesting that perhaps motion information is processed in a distinct manner from other mammals. One striking difference between mice and primates is the presence of a strong functional organization in the visual cortex: rodents lack a functional organization beyond retinotopy, whereas primates and carnivores have a columnar organization for orientation, direction, and spatial frequency (Hubel and Wiesel, 1962, 1968; Malonek et al., 1994; Girman et al., 1999; Issa et al., 2000; Ohki et al., 2005; Nauhaus et al., 2012). Although it is tempting to link this difference in the organization of sensory information across species to changes in motion processing, rats, which share the lack a functional organization in visual cortex, are able to perform motion discrimination tasks (Douglas et al., 2006). Additionally, a more recent study has demonstrated that mice are able to discriminate motion in opposite directions using a different training paradigm (Marques et al., 2018).

We set out to determine whether mice could discriminate motion using classical conditioning and to see whether their report of motion depends on the recent history of motion stimulation. We demonstrate here that mice can accurately discriminate motion of opposite directions and that their report is subject to the waterfall illusion: e.g., prolonged visual stimulation with rightward motion induces mice to report that leftward motion exists for conditions in which no coherent motion is presented. These results demonstrate that motion processing in the mouse visual system, although differing in functional organization from primates, exhibit similar integrative and competitive processes, which result in the illusion of motion to stationary stimuli following prolonged stimulation.

\section{Materials and Methods}

\section{Preparation of animals}

Two adult female C57BL/6 and two adult PV-Cre;ChR2 (1 male, 1 female) on a C57BL/6 background mice (4-18 months) were used in these experiments. To immobilize the head during behavior, a titanium bar was placed on the skull and secured with dental acrylic under isoflurane (1-3\%) anesthesia (Samonds et al., 2018). All procedures were approved by the Institutional Animal Care and Use Committee and conformed to National Institutes of Health standards.

\section{Visual stimuli}

We used a DepthQ HDs3D2 projector (DepthQ/Lightspeed Design) with a refresh rate of $120 \mathrm{~Hz}$ at full HD resolution $(1920 \times 1080)$, operating in gray-scale mode (mean luminance $=59.75 \mathrm{~cd} / \mathrm{m}^{2}$ ). Stimuli were either rear-projected onto a polarization-preserving screen (DaLite 3D virtual black rear screen fabric, model \#35929) or front-projected onto a silver polarization-preserving screen (Severtson, SeVision 3D GX, 2.2 Silver). One pixel subtended $0.1^{\circ}$ at a viewing distance of $22 \mathrm{~cm}$.
Black and white dot motion stimuli of varying coherence were generated using MATLAB (MathWorks) and Psychtoolbox (Brainard, 1997). Each of 800 dots of $1^{\circ}$ of visual field in diameter were displayed within a $60^{\circ}$ square aperture in front of the mouse, appeared in random locations, and moved in a given direction for a dot lifetime of six frames. The dot lifetime restricted the highest possible coherence to $86 \%$ (Bischof et al., 1999). Each trial consisted of a $3 \mathrm{~s}$ visual stimulation period and were separated by an interstimulus period lasting $10 \mathrm{~s}$ plus a random interval drawn from an exponential distribution with a mean of $10 \mathrm{~s}$. This random interval prevents the mice from predicting the time point of reward delivery (Khastkhodaei et al., 2016; Jurjut et al., 2017). During preliminary motion discrimination training, we displayed dots with $86 \%$ coherent motion and $100 \%$ Michelson contrast during the stimulation period, and we presented a mean gray screen during the interstimulus period. During motion aftereffect tests, we presented dots of varying coherent motion ranging from 0 to $51 \%$ during $4 \mathrm{~s}$ of stimulation with $100 \%$ contrast, and we presented $0 \%$ coherent motion dots, $86 \%$ coherent leftward moving dots, or $86 \%$ coherent rightward moving dots at $30 \%$ contrast during the randomly timed interstimulus period. There was a mean gray screen gap of $0.5 \mathrm{~s}$ between the adaptation stimulus and the test stimulus conditions, and a gap of $5 \mathrm{~s}$ following stimulation, in which a water reward was delivered.

\section{Training paradigm}

All animals were water-restricted for 1 week before training and the weights of the animals were maintained within $30 \%$ of the original body weight (Guo et al., 2014). The animals were acclimated to the training apparatus during the restriction period. Animals walked on a floating Styrofoam ball while they were head-fixed (Dombeck et al., 2007). Classical conditioning was used to pair visual motion to water delivery (Khastkhodaei et al., 2016; Jurjut et al., 2017). Initially, we presented two different motion conditions, upward and leftward, pairing leftward with a water reward. Over a few weeks of training sessions, mice associated the reward with leftward motion and began to lick before the water being delivered at the end of stimulation and only for the leftward moving stimuli. Once trained to associate water with leftward motion, the mice quickly adapted (typically less than a few days) to small changes in the experimental paradigm (e.g., changes in the direction of unrewarded stimuli, coherence, adapting experiments). Licking was measured using a piezoelectric sensor attached to the reward delivery system (Schwarz et al., 2010; Khastkhodaei et al., 2016; Jurjut et al., 2017). The water was delivered in a flexible catheter that would bend upward and downward as the mouse licked. All behavior was quantified as single lick events and lick rates that were detected using a threshold based on the typical output of the piezoelectric sensor. For each stage of training, we gradually exposed the mice to any particular change (direction of motion, coherence, adapter) sometimes combining the changes with the original conditions until they were conditioned to the test stimuli. 
A

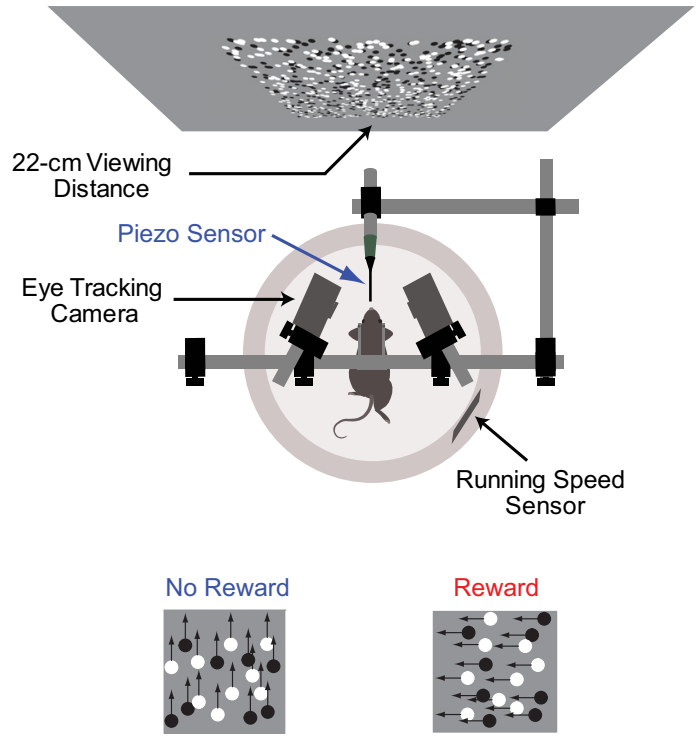

B

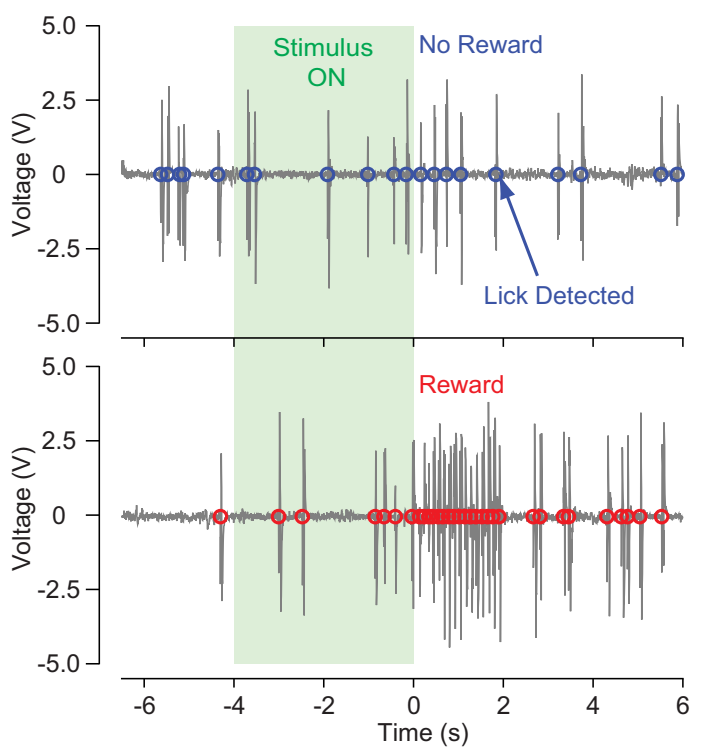

Figure 1. Experimental setup. A, Random-dot motion stimuli were projected in front of mice running on a floating track ball. A water reward was given to mice following the presentation of only motion in the leftward direction. $\boldsymbol{B}$, Licks were measured using a piezoelectric sensor attached to the water delivery system.

\section{Eye tracking}

During all of the experimental procedures and training, an IR camera recorded video of the eye movements at 30 $\mathrm{Hz}$. An artificial eye with a diameter of $3.1 \mathrm{~mm}$ was used to calibrate eye position estimates. Eye positions were extracted (based on the center of the pupil) and analyzed using custom MATLAB software (Samonds et al., 2018). We did not find any changes in eye position or velocity that correlated with the direction of motion of presented stimuli because we used a motion speed (30 degrees/s) outside of the range of measurable ocular kinetic reflex gains in mice (Tabata et al., 2010).

\section{Statistical analysis}

Using the least-squares curve fit function in MATLAB, we fit the following sigmoid function for all mean lick counts $(L)$ versus coherence $(c)$ data:

$$
L=(M-u) \frac{1}{1+e^{-b\left(c-c_{0}\right)}}+u
$$

where $M$ and $u$ determine the vertical position of the sigmoid (maximum and minimum lick counts), $b$ determines the slope of lick counts with coherence, and $c_{o}$ determines lateral position (bias) of the sigmoid (coherence). This function was also used to fit a function for $d^{\prime}$ versus coherence and an inverted sigmoid function was used to fit a function for latency versus coherence. Confidence intervals $(\mathrm{Cls})$ and significance were estimated using a bootstrap procedure. We resampled our datasets randomly with replacement 1000 times to generate bootstrap distributions. The $68 \%$ Cls (SE) were defined as the resampled data corresponding to the $(16,84)$ percentile range of the bootstrap distributions.

\section{Results}

Here we examined whether sensory adaptation alters the perception of motion in the mouse. We initiated our experiments by first training animals to discriminate leftward and upward motion using classical conditioning (Khastkhodaei et al., 2016; Jurjut et al., 2017) and then slowly rotated the upward motion to the right until the task was a leftward and rightward motion discrimination. Once mice reached a criterion performance $\left(d^{\prime} \geq 0.8\right)$ in this task, we measured how the history of sensory stimulation impacted their ability to discriminate these directions.

\section{Training mice to discriminate opposite directions}

Previous studies have reported that it is difficult to train mice to perform direction discrimination tasks when the motion directions are opposing whereas they can perform tasks when the directions are orthogonal (Douglas et al., 2006; Stirman et al., 2016). With these studies in mind, we first paired a water reward with leftward motion and presented an upward motion stimulus without any reward. We placed head-fixed mice on a ball floating on air (Fig. $1 A$ ) and measured the licking behavior of animals using a piezoelectric sensor placed on a waterspout (Fig. 1B).

Motion stimuli were presented for $3 \mathrm{~s}$, and initially animals licked randomly and only vigorously once water came out of the spout (Fig. 2A, Untrained). For all naive mice, lick rate increases occurred $400 \mathrm{~ms}$ after the water exited the spout (Untrained phase latency range: +402 to +445 ms; Fig. 2A, dashed black line). Latency for licking was defined as the time to reach $20 \%$ of the peak lick rate relative to reward onset. Each day, we trained mice using 96 trials, 48 rewarded leftward and 48 unrewarded upward motion conditions. Within 1 week, the mice started to associate the stimulus with the reward, but initially 

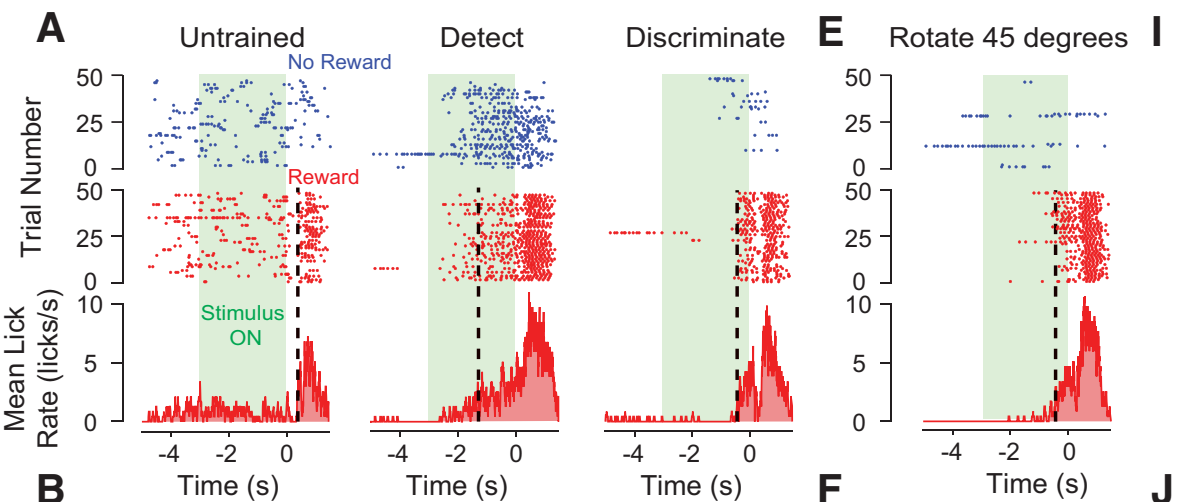

Rotate 45 degrees
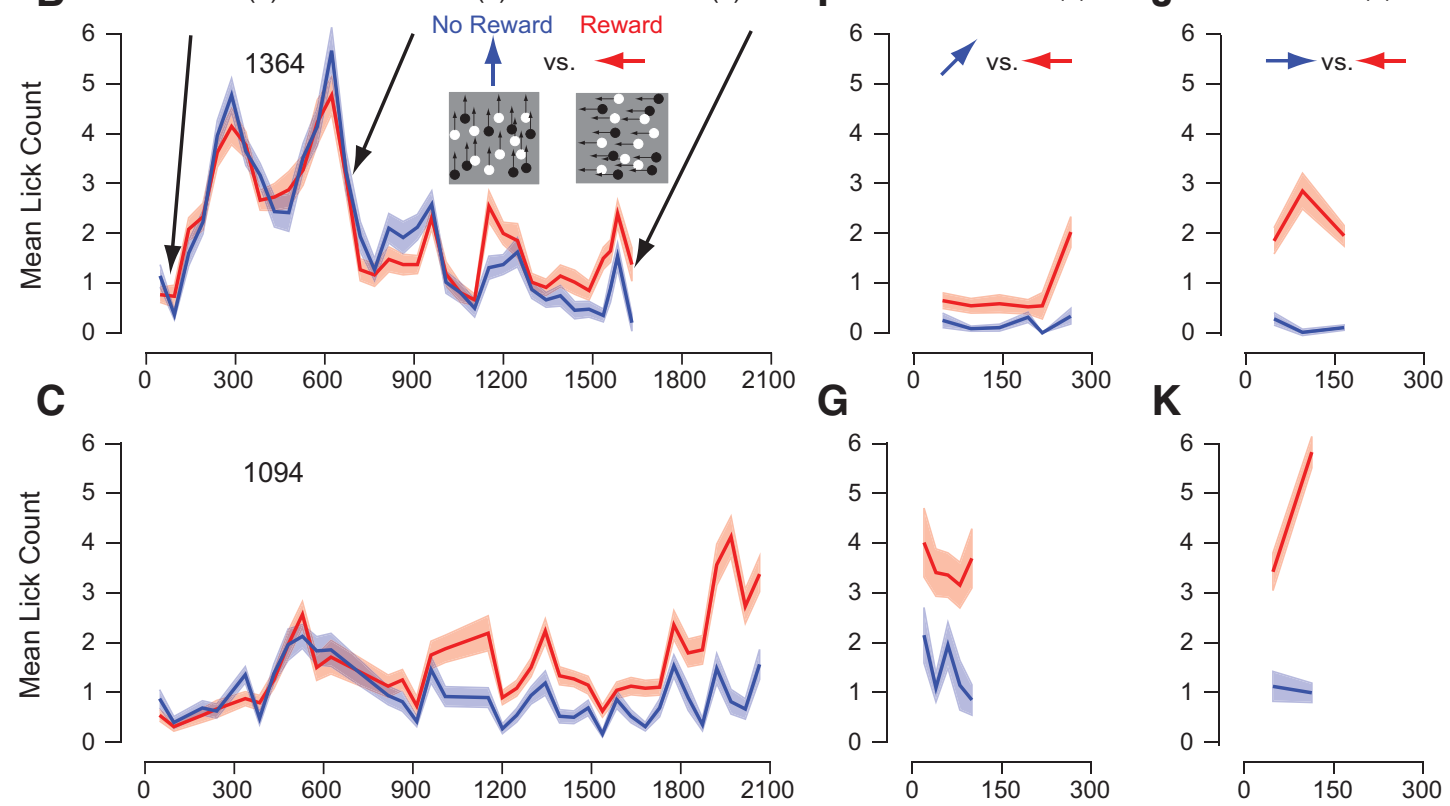

D
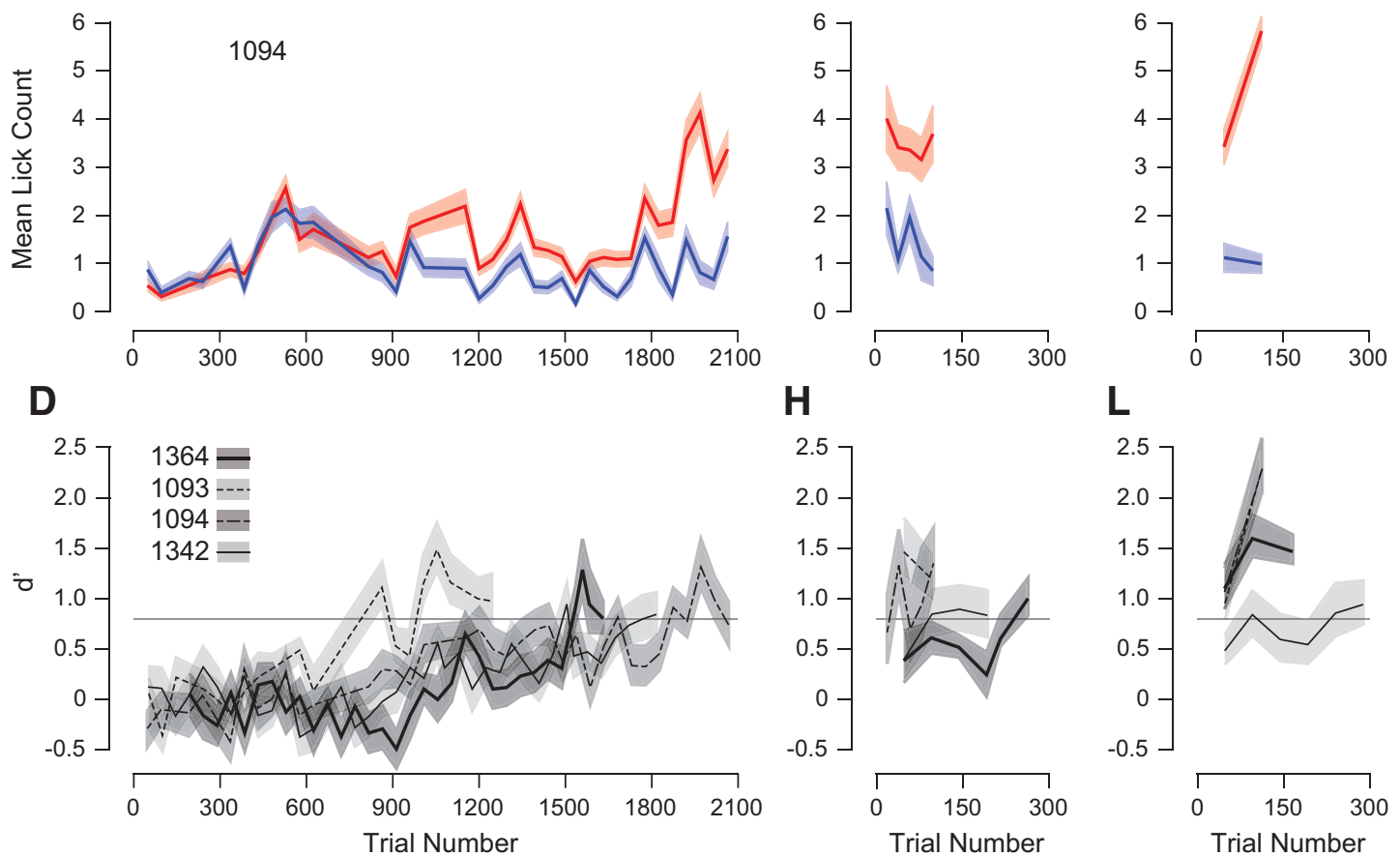

Figure 2. Classical conditioning paradigm for learning to discriminate the direction of motion. $\boldsymbol{A}$, Example lick raster plots and histograms for 3 sessions for one of the mice (1364). Initially (Untrained), this mouse licked spontaneously and infrequently before and rigorously after the reward was delivered (left). After several hundred trials, this mouse began licking more frequently in anticipation of a water reward for both moving stimuli (center, Detect). Finally after 1500 trials, the mouse licked in anticipation for only the rewarded leftward motion stimulus (right, Discriminate). Vertical dashed line is the lick onset latency. B, Mean lick count from -1 to $0.2 \mathrm{~s}$ for rewarded (red) and unrewarded (blue) directions of motion over all initial sessions of training for the data shown in $\boldsymbol{A}$, which is a mouse that decreased licking to the unrewarded condition (blue). $\boldsymbol{C}$, Mean lick count for a mouse that increased licking to the rewarded condition (red). $\boldsymbol{D}, d^{\prime}$ Calculated for each session from the lick counts shown in $\boldsymbol{B}$ and $\boldsymbol{C}$, as well as from lick counts measured from the other two mice. Horizontal dashed line is the training criterion. $\boldsymbol{E}$, After the mice learned to discriminate upward from leftward motion, we slowly rotated the unrewarded stimulus. An example lick raster plot and histogram is shown for Mouse 1364. $\boldsymbol{F}-\boldsymbol{H}$, There was still a difference in lick count and significant $d^{\prime}$, and these values even continued to increase when rotating the unrewarded stimulus by $45^{\circ}$. $I$, After the mice learned to discriminate oblique from leftward motion, we rotated the unrewarded stimulus another $45^{\circ}$ so the unrewarded condition was rightward motion. Again, an example lick raster plot and histogram is shown for Mouse 1364. $\boldsymbol{J}-\mathbf{L}$, Again, there was still a difference in lick count and significant $d^{\prime}$, and discrimination even continued to improve for leftward versus rightward motion. All error bars are bootstrapped SEM and $d^{\prime}$. 
A

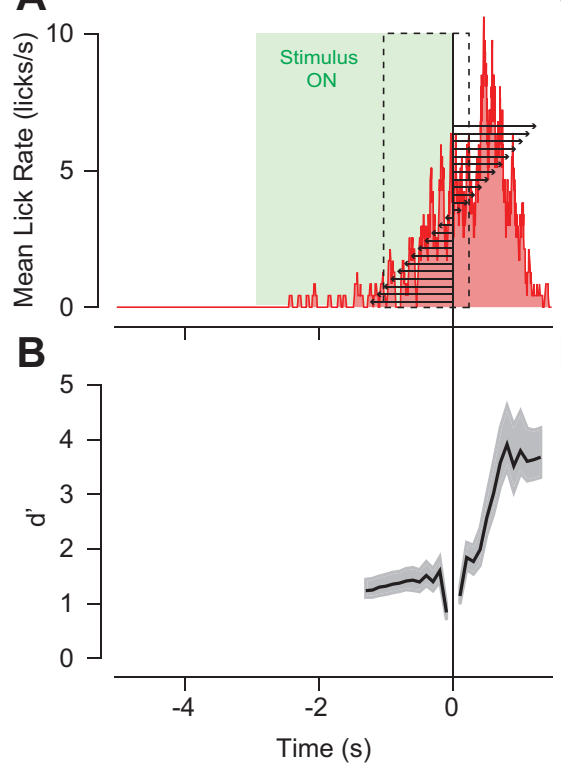

C

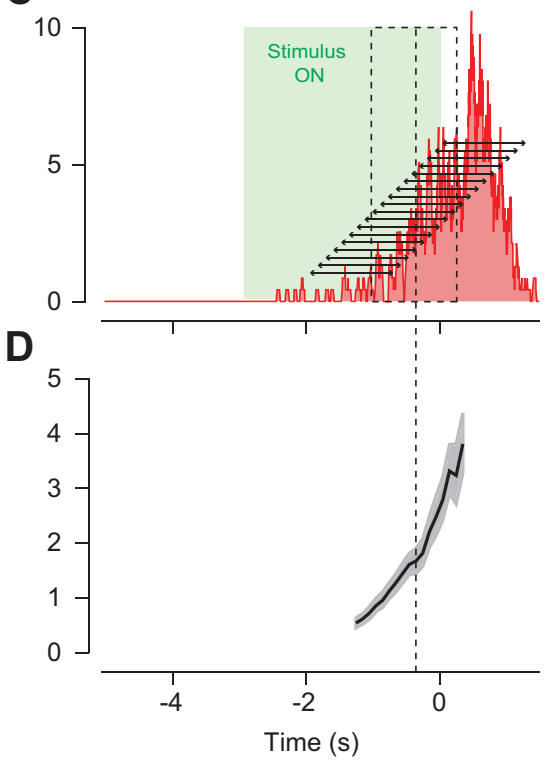

Figure 3. Dependence of discrimination of lick count window. $\boldsymbol{A}$, The lick rate over time for the rewarded condition increases before the end of the stimulus presentation (green), and continues increasing at an even greater rate 400 ms after the reward is delivered. We measured $d^{\prime}$ in progressively larger windows (arrows) on both side of reward onset. The window used in Figure 2 is shown as a dashed black box. $\boldsymbol{B}$, The resulting $\boldsymbol{d}^{\prime}$ measurements between the rewarded and unrewarded conditions for the increasing window sizes described in $\boldsymbol{A}$. $\boldsymbol{C}$, We also measured $\boldsymbol{d}^{\prime}$ while moving a window with a fixed size of $1.2 \mathrm{~s}$ from $-800 \mathrm{~ms}$ before to $+800 \mathrm{~ms}$ after reward onset. $\boldsymbol{D}$, The resulting $d^{\prime}$ measurements for the window positions described in $\boldsymbol{C}$. The vertical dashed line is the center of the window used in Figure 2. Shaded regions are the bootstrapped SE of $d^{\prime}$.

without distinguishing between the rewarded and unrewarded direction of motion. The mice reduced their spontaneous licking and started to lick soon after the motion stimulus turned on and more vigorously after the reward was delivered for the rewarded condition (Fig. 2A, Detect). The mice anticipated a reward once detecting a motion stimulus by starting to lick over a second (Detection phase latency range: -1394 to $-2636 \mathrm{~ms}$ ) before the reward was delivered (Fig. 2A, Detect, black dashed line). After a couple more weeks of conditioning, the mice began to associate only the leftward motion stimulus with the water reward (Fig. 2A, Discriminate). Mice continued to lick before the appearance of the water stimulus (Fig. $2 A$, Discriminate, black dashed line), but did not start licking as quickly as during the detection phase (Discrimination phase latency range: -385 to $-633 \mathrm{~ms}$ ).

Another effect of training was that the lick rate difference between the rewarded and unrewarded stimulus progressively increased. We measured lick count during the period between -1 and $+0.2 \mathrm{~s}$ relative to reward onset. This window was chosen based on: (1) the latency of discriminatory licking relative to reward onset being $<1$ $s$, (2) the latency of licking relative to reward onset for unconditioned mice being $>400 \mathrm{~ms}$, and (3) a bifurcation observed in lick rate around $400 \mathrm{~ms}$ after reward onset suggesting a distinction between licking based on the stimulus and licking based on the delivery of the water (Fig. 2A,E,I). As training progressed over 3-4 weeks, mice decreased their lick count to the unrewarded direction of motion (Fig. 2B, blue) and/or increased their lick count for the rewarded direction of motion (Fig. $2 C$, red). To quantify the degree to which lick rate reflected a discrimination between leftward and upward motion we computed $d^{\prime}$ between lick counts on a day-by-day basis (Fig. 2D). Over the conditioning period, $d^{\prime}$ slowly increased reaching values consistently $>0.8$, which was our criterion to begin the shaping process.

Our analysis of behavioral performance does depend on the timing over which we measured lick rate. To examine how our analysis window affected our discrimination measurements we measured $d^{\prime}$ for the licking behavior at the end of this training period (Figs. 2I, 3A) with progressively larger windows starting from each side of reward onset. We find that there are minor changes in $d^{\prime}$ as we increase the duration of the pre-reward window size (Fig. 3A, leftward arrows), with a slight decrease in $d^{\prime}$ as we include longer pre-reward intervals (Fig. $3 B$, left). Including increasing amounts of post-reward intervals (Fig. $3 A$, rightward arrows) has little initial influence on $d^{\prime}$ until $400 \mathrm{~ms}$, at which time $d^{\prime}$ increases dramatically (Fig. $3 B$, right). At that time, the mouse was responding to reward delivery by licking vigorously rather than anticipating a reward because of the stimulus. We also examined how shifting a window with a fixed size of $1.2 \mathrm{~s}$ varied $d^{\prime}$ estimates (Fig. 3C). As we moved the window progressively closer to reward onset, $d^{\prime}$ increased at a constant rate. As the leading (latest) edge of the window approached $100 \mathrm{~ms}$ after reward onset, $d^{\prime}$ changed minimally (Fig. 3D, center of window at $500 \mathrm{~ms}$ before reward onset: vertical dashed line). When the leading edge of the window reached $400 \mathrm{~ms}$ after reward onset, $d^{\prime}$ increased at a rate more rapidly than before reward onset because the mouse was responding to reward delivery rather than licking in anticipation of a reward. Both analyses support 
our choice of the interval of -1 to $+0.2 \mathrm{~s}$ (Fig. $3 A$, black dashed box) to measure lick behavior, which includes the majority of the anticipatory licking (Fig. $3 A$, red) that was induced by our conditioning paradigm.

For this study, we were primarily interested in how the history of sensory information influences motion perception. For example, in the waterfall illusion, prolonged downward motion elicits a perception of upward motion, but may not alter perceptions of rightward and leftward motion. Although our classical conditioning paradigm demonstrates that mice can successfully discriminate leftward and upward motion as previously reported (Douglas et al., 2006; Stirman et al., 2016), we needed to observe mice discriminating leftward and rightward motion to induce a motion aftereffect. To change our task to one in which mice discriminate motion along the horizontal axis, we used a paradigm over a series of days in which we rotated the upward moving stimulus toward the rightward direction. Initially, we rotated the stimulus at $45^{\circ}$ and mice could still discriminate the leftward and oblique directions (Fig. 2E-H). We continued rotating the stimulus until the mice could distinguish leftward and rightward directions of motion (Fig. $2 /-L$ ). The mice rapidly generalized their discriminatory lick behavior to the change in direction of motion for the unrewarded condition (Fig. $2 H, L)$ and even continued to improve their discrimination over these periods (Fig. $2 L$ ). For the last data point in Figure $2 L$, we included $d^{\prime}$ measurements from lick behavior following all the subsequent stages of training described below to illustrate that the mice retained their discriminability or even had improved performance although the task continued to become more difficult because we reduced motion coherence (described in the next section).

\section{Using the motion aftereffect to bias motion discrimination}

Once mice could discriminate leftward and rightward moving stimuli, we measured the impact of long-term motion adaptation and changing the strength of motion on behavior. To examine how the history of motion stimulation impacts the discriminability behavior of the mice, we varied the coherence and direction of dots during an adaptation phase and during the test phase. The adapting phase occurred during the interstimulus period of the conditioning paradigm (Fig. 4A) and was composed of noncoherent motion or full coherent motion in the rightward or leftward directions at low contrast. The test phase was composed of moving dots of systematically different coherence with high contrast (Douglas et al., 2006; Stirman et al., 2016; Marques et al., 2018). Coherence is defined as the percentage of dots moving in the same leftward or rightward direction. The rest of the dots moved in random directions.

Licking behavior was systematically related to test coherence when the adapting motion contained $0 \%$ coherence dots (Fig. 4B-D). As test coherence for leftward motion increased, lick count increased until saturating at a maximum number of licks (Fig. $4 B$, right side of each plot). As test coherence for rightward motion increased, lick count decreased until saturating near zero licks (Fig. $4 B$, left side of each plot). Although maximum mean anticipatory lick counts varied among mice (2-6 licks), their discriminability was similar. We measured $d^{\prime}$ for lick counts for each mouse to stimuli of equal coherence, but opposite direction (Fig. 4C). As expected based on lick counts, $d^{\prime}$ increased with increasing test coherence maxing out at $d^{\prime}=1-2.5$. Additionally, the mice generally started to lick earlier for higher compared to lower coherence leftward motion stimuli. The corresponding latencies for lick behavior to leftward motion stimuli in Figure $4 B$ are shown in $4 D$. All of the mice started licking sooner for leftward motion with higher coherence.

To examine whether preceding motion altered their behavior, we measured responses to the test stimulus when there was full coherence motion in the leftward or rightward direction during the adapting phase (Fig. $5 A$ ). As with the previous experiments, the mouse was then rewarded following only leftward moving test stimuli. The adapting motion had systematic effects on the licking behavior of the mice in response to the test stimulus. In humans, exposure to rightward motion causes the misperception of leftward motion to stationary stimuli and exposure to leftward motion causes the misperception of rightward motion to stationary stimuli. Based on psychometric functions observed for human motion aftereffect studies, we predicted that coherent motion during the adapting phase would shift the lick count versus coherence functions (Fig. 4B) to the left or right if the motion of the adapter is rightward or leftward, respectively (Blake and Hiris, 1993; Van Wezel and Britten, 2002; Czuba et al., 2011). Consistent with the motion aftereffect illusion, mice licked more in response to stimuli at zero coherence following rightward adaptation than leftward adaptation (Fig. 5B, magenta vs cyan traces). We quantified differences in lick rates between the rightward (magenta) and leftward (cyan) adapting conditions by comparing the lick counts for the four coherences along the steepest slope of the response curves in Figure $5 B$, where the mice had the most uncertainty (e.g., 0-25.7\%; Fig. 6A, inset). Within this range for all of the mice, there was significantly more licking for the rightward adapting condition versus the leftward adapting condition (Fig. $6 A$, magenta vs cyan data points; $p<0.01$, bootstrapping). To further evaluate our prediction, we measured whether adaptation altered lick behavior by fitting a sigmoid function to the data and (1) computing the mean difference in coherence at the halfway point between the minimum and maximum lick counts of the sigmoid fits and (2) calculating the mean lick count difference of the fits at the halfway point of the leftward adapting sigmoid fit (Fig. 6B). Both characterizations (horizontally and vertically) of the sigmoid shift are statistically significant $(p<0.05)$ for all mice based on bootstrap analysis. For some of the mice, the zero coherence adapted sigmoid function is shifted to the right relative to zero coherence (Fig. 5B, Mouse 1364). This is likely because these mice only licked when there was leftward motion detected. Some mice licked less when there was high coherence for rightward motion and licked more when there was high coherence for leftward motion 


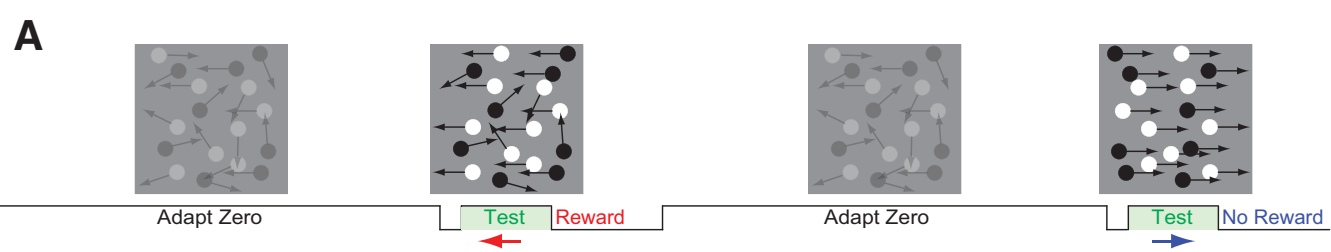

B
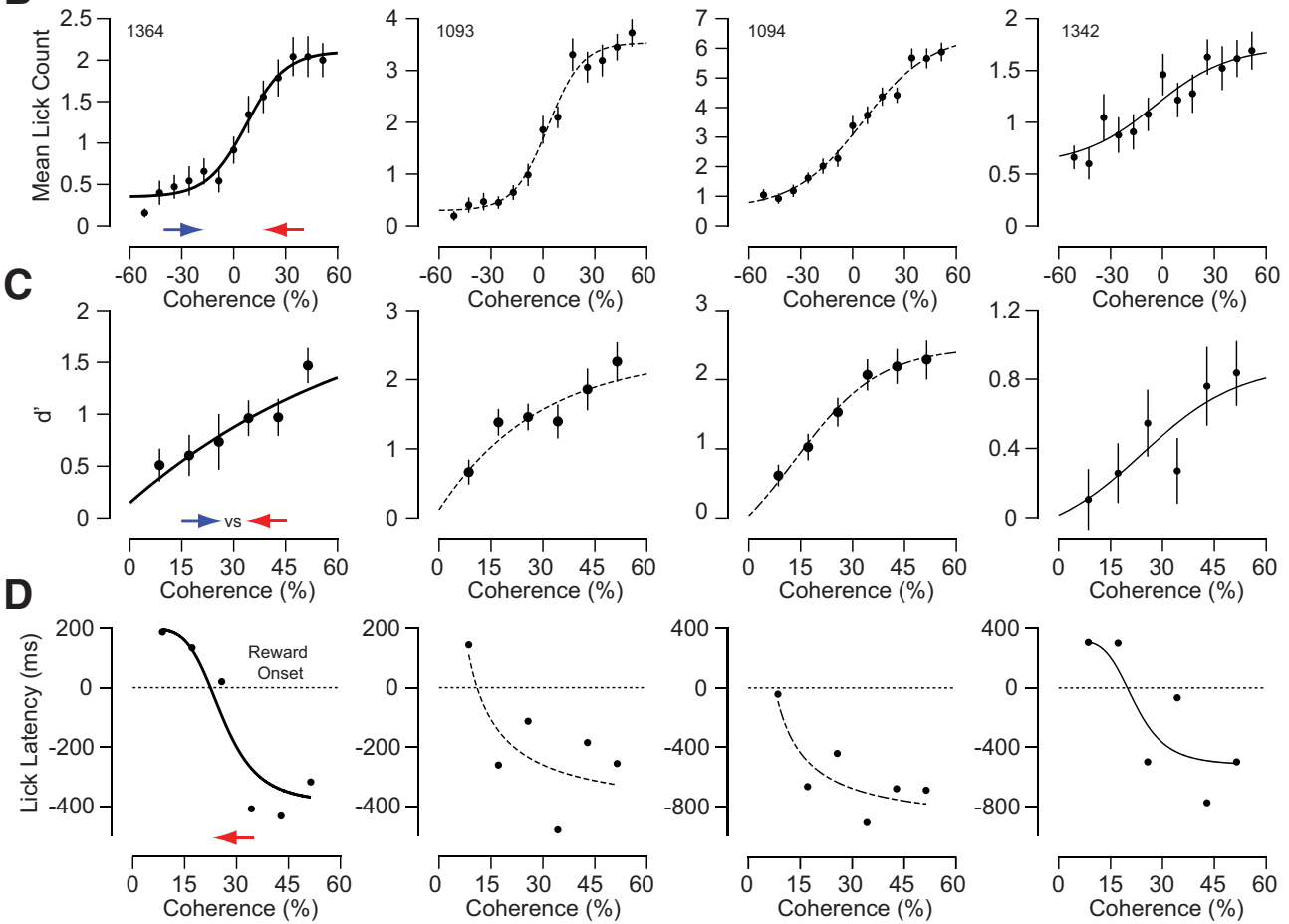

Figure 4. Motion discrimination improves with increasing random dot motion coherence. A, Mice were shown a 30\% contrast zero coherence adapting stimulus for at least $10 \mathrm{~s}$ before being shown a $4 \mathrm{~s} 100 \%$ contrast test stimulus of varying coherence. $\boldsymbol{B}$, Lick count increased monotonically as a sigmoid function versus coherence for all of the mice (solid and dashed black lines). Error bars are bootstrapped SEM ( $n=62-70$ repeats for each condition). C, $d^{\prime}$ also increased monotonically as a sigmoid function versus coherence for all of the mice (solid and dashed black lines). Error bars are bootstrapped SE of $d^{\prime}$. $\boldsymbol{D}$, The mice all licked sooner for higher coherence leftward motion as a sigmoid function of coherence as well.

(Fig. 5B, Mouse 1094). Despite these intersubject differences, we still observe consistent shifts in lick behavior that depend on the adaptation direction. Overall, our analysis supports that the adapter shifted the response curves in the expected directions if there were a motion aftereffect for mice.

We designed our motion aftereffect paradigm so that the mice would ignore the adapting stimulus by lowering the contrast relative to the test stimulus (Fig $5 A$ ). Nonetheless, the adapter stimuli could have changed motivation or arousal systematically that would produce a difference between the rightward and leftward lick counts consistent with Figure 6, $A$ and $B$. For example, if the mice associated rightward motion during the adapting phase with increased reward, they might lick more for all test conditions or they might have increased sensitivity for all leftward test conditions. This behavior would produce an upward shift, or multiplicative increase, in the licking behavior with coherence.

To determine whether the adapting stimuli caused behavioral changes such as increased or decreased motivation or arousal, we tested for differences in lick counts at high coherences for both rightward and leftward motion, as well as differences in the asymptotes of our sigmoid fits. We quantified differences in lick counts between rightward (magenta) and leftward (cyan) adaption for high-coherence rightward test motion (Fig. 6C, inset) and for high-coherence leftward test motion (Fig. 6E, inset). In both cases for all four mice, there were no significant differences in lick counts (Fig. 6C,E, magenta vs cyan data points; $p>0.05$, bootstrapping). Correspondingly, we tested for differences in the lower (Fig. $6 D$, inset) and upper (Fig. 6F, inset) asymptotes of our sigmoid fits for rightward (magenta) and leftward (cyan) adaptation. For all four mice, there were no significant differences in both the lower and upper asymptotes of the sigmoid fits for rightward versus leftward adapting conditions (Fig. $6 D, F ; p>0.05$, bootstrapping). Overall, our data demonstrate that opposite directions of motion in the adapting stimuli resulted in significant lateral shifts, but not in any significant upward or downward shifts, in how licking behavior changes with motion coherence.

If mice licked more often for leftward versus rightward adaptation during the adapting phase (expecting a reward 


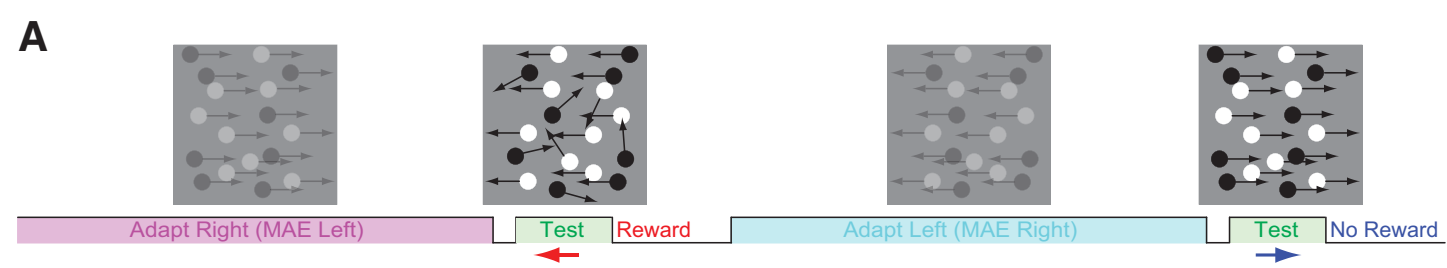

B

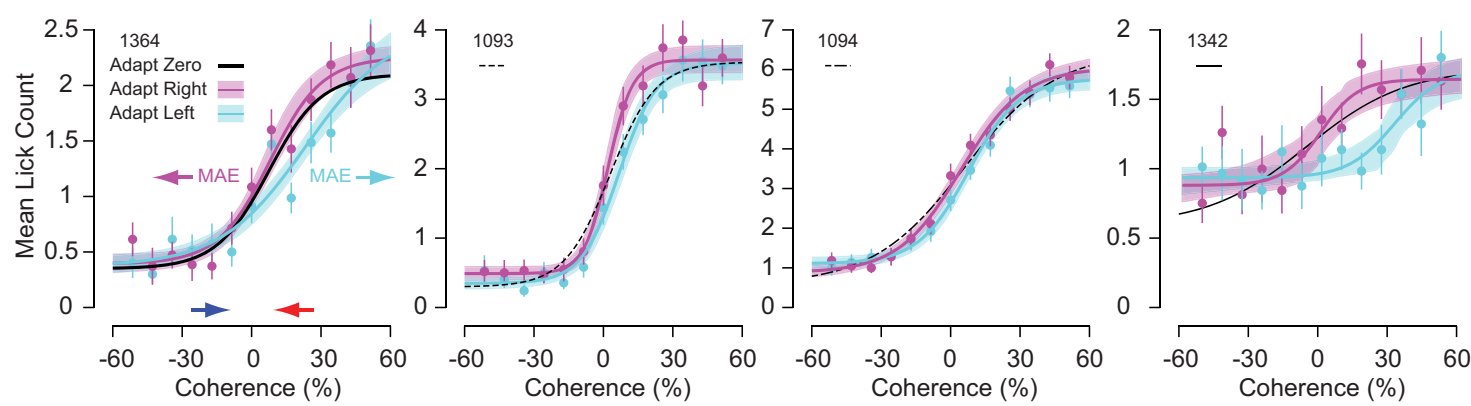

Figure 5. Motion discrimination is biased by previous prolonged exposure to motion stimuli. A, Mice were shown a $30 \%$ contrast fully coherent adapting stimulus for at least $10 \mathrm{~s}$ before being shown a $4 \mathrm{~s} 100 \%$ contrast test stimulus of varying coherence. $\boldsymbol{B}$, Mean lick counts for rightward (magenta) and leftward (cyan) adapting conditions. The corresponding sigmoid fits from Figure $4 B$ for zero coherence adapted lick counts versus coherence are displayed as solid and dashed black lines. The mice licked more for rightward adapting stimuli (magenta) because this should produce a leftward motion aftereffect, which corresponds to the rewarded condition. The mice licked less for leftward adapting stimuli (cyan) because this should produce a rightward motion aftereffect, which corresponds to the unrewarded condition. Error bars are SE and shaded bands for magenta and cyan lines are the bootstrapped SE of sigmoid fits ( $n=62-70$ repeats for each condition).

based on their past conditioning), they might be more fatigued and lick less often during the test phase leading to less licking for leftward (cyan) versus rightward (magenta) adapted behavioral curves. Therefore, to directly determine if mice reacted to the adapting stimuli in our experiments, we investigated lick behavior during the adapting phase. Figure 7 shows how the lick rate varies over the time course of a trial with respect to rightward (magenta) versus leftward (cyan) adaptation. The trial is broken up into three parts: (1) Adapt Phase, the first $10 \mathrm{~s}$ of adaptation (random interval of at least $10 \mathrm{~s}$ ) aligned to the onset of the adapter stimulus (at $5 \mathrm{~s}$ after the reward time for previous trials); (2) Test Phase, the final $5 \mathrm{~s}$ of adaptation and the first $2 \mathrm{~s}$ of the test stimulus aligned to stimulus onset; and (3) Reward Phase, the final $2 \mathrm{~s}$ of the test stimulus and $1 \mathrm{~s}$ following reward onset (at $0 \mathrm{~s}$ ). First, the lick rate decays following licking in response to rewards from the previous trial (Fig. 7, peak farthest to the left). Then, there is no apparent change in lick rate with respect to the onset of adapter stimuli during the adapt phase (Fig. 7, gray). The mice only lick spontaneously and infrequently during the adapting phase and then there is either no change in lick behavior (Fig. 7, green, Mice 1364 and 1342), a decrease from spontaneous licking (Fig. 7 , green, Mouse 1093), or a transient increase from spontaneous licking at stimulus onset (Fig. 7, green, Mouse 1094). Lastly, licking increased for all four mice preceding reward onset (Fig. 7, right side of green region) and the licking is greater for rightward adaptation (Fig. 7, magenta) compared to leftward adaptation (Fig. 7, cyan). To confirm that there was no direction-dependent reaction to the adapter stimulus, we compared the lick rates between rightward and leftward adaptation and found that licking was infrequent $(<0.6$ licks $/ \mathrm{s})$ and not significantly different between conditions (Fig. 8, magenta vs cyan data points; $p>0.05$, bootstrapping). These observations suggest that the mice were ignoring the low contrast adapter stimuli.

\section{Discussion}

We have demonstrated that mice can accurately distinguish between leftward and rightward stimuli by using classical conditioning paradigm to associate water reward with motion. While rats and other animals have previously been shown to perform direction discrimination tasks (Douglas et al., 2006; Stirman et al., 2016), early attempts to train mice to perform opposite direction discrimination were not successful (Douglas et al., 2006). This failure could either be ascribed to differences in the neuronal representation for motion or to issues with the training paradigm. We used a two stage protocol to train the animals in which animals initially learned to distinguish horizontal and vertical motion and then a protocol was used in which we rotated, over a period of days, the unrewarded upward motion stimulus until the animals were performing the task using only horizontal motion. Because another recent study used licking without rotating the direction of motion to successfully train mice to discriminate motion in opposite directions (Marques et al., 2018), our use of licking behavior to test for motion discrimination performance may also be an important factor to capture this ability in mice. Once the animals were trained for this task, we were also able to demonstrate that their report is subject to the waterfall illusion: e.g., prolonged visual stimulation with rightward motion induces mice to report that leftward motion exists for con- 

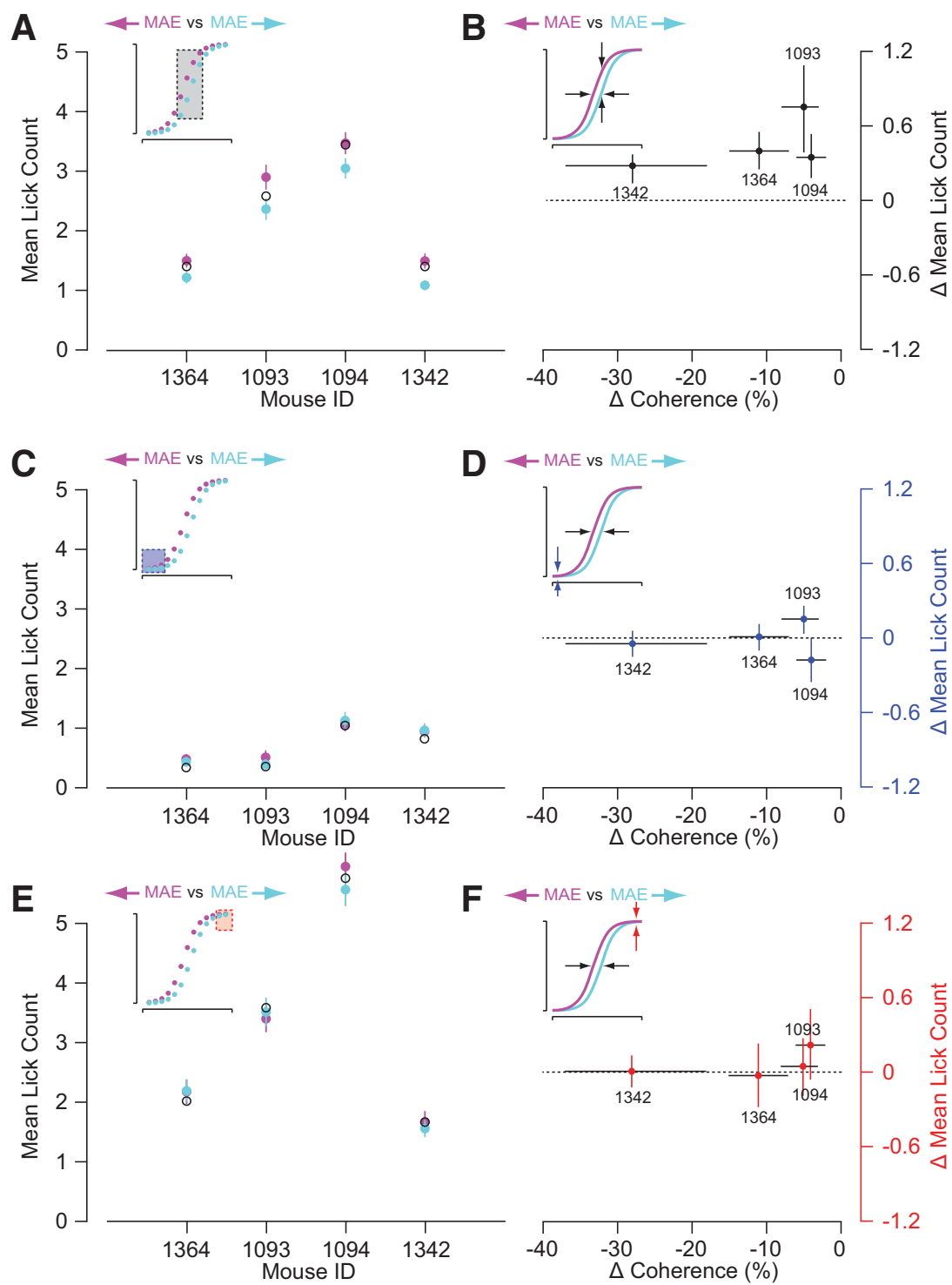

Figure 6. Licking behavior was consistent with a motion aftereffect. $\boldsymbol{A}$, Average lick counts for the four coherences along the steepest slope in Figure $5 B$ for the rightward (magenta) and leftward (cyan) adapting conditions (inset, gray box). For all four mice, the rightward-adapted conditions had significantly more licking than the leftward-adapted conditions $(\boldsymbol{p}<0.01)$. $\boldsymbol{B}$, Measurements of the shifts in the coherence bias and mean lick rate following rightward and leftward adaptation, based on sigmoid fits (inset). The dashed line indicates no change in lick rate. All data points represent upward and leftward shifts between the functions for the four mice and were significantly above $(y$-axis) and below ( $x$-axis) zero, respectively $(p<0.05)$. $\boldsymbol{C}$, Average lick counts for the three highest coherences for rightward motion in Figure $5 B$ for the rightward- (magenta) and leftward- (cyan) adapted conditions (inset, blue box). For all four mice, there was no significant difference between the rightward- and leftward-adapted conditions $(p>0.05)$. $\boldsymbol{D}, A s$ in $\boldsymbol{B}$, but the ordinate plots differences in the lower asymptotes of the sigmoid function. For all four mice, there was also no significant difference in the lower asymptotes of the sigmoid function (inset) between the leftward-adapted function (magenta) compared with the rightward-adapted function (cyan; $p>0.05$ ). $\boldsymbol{E}$, Average lick counts for the two highest coherences for leftward motion in Figure $5 B$ for the rightward- (magenta) and leftward- (cyan) adapted conditions (inset, red box) were also not significantly different $(p>0.05$ ). $\boldsymbol{F}$, As in $\boldsymbol{B}$ and $\boldsymbol{D}$, but the ordinate plots the differences in the upper asymptotes. There was no significant difference in the upper asymptotes of the sigmoid function (inset) between the leftward-adapted function (magenta) compared with the rightward-adapted functions (cyan; $p>0.05$ ). $\boldsymbol{A}, \boldsymbol{C}$, and $\boldsymbol{E}$, Error bars are bootstrapped SE of the average and open black circles are the lick counts for the $0 \%$ coherence adapting condition ( $n=62-70$ repeats for each condition). $\boldsymbol{B}, \boldsymbol{D}$, and $\boldsymbol{F}$, Error bars are bootstrapped SE of sigmoid fit parameters.

ditions in which no coherent motion is presented. Our results indicate that the mouse is able to discriminate leftward from rightward motion and that discrimination is susceptible to recent motion history.
The performance of our mice in discriminating the direction of motion with reduced coherence are similar to what has been observed in previous studies (Douglas et al., 2006; Stirman et al., 2016; Marques et al., 2018). 

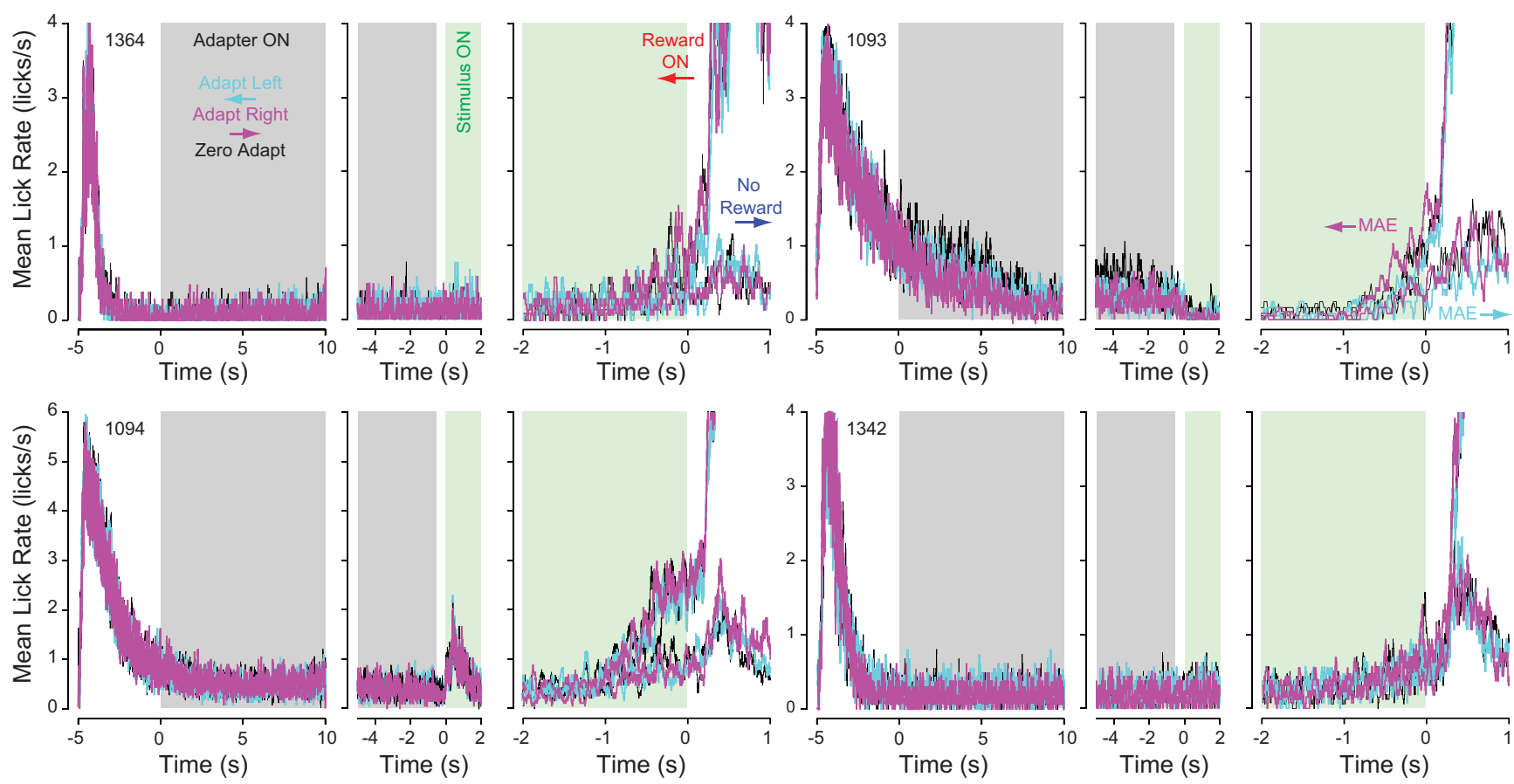

Figure 7. The influence of the adapter stimuli on licking behavior. The average lick rate over the period of the experiment is shown to illustrate differences in lick behavior between the three adapting stimuli (left, right, and 0) during the adapt (left), test (center), and reward (right) phases. Lick rates differ between rightward (magenta) and leftward (cyan) adapting stimuli only before reward onset (right plots, $0 \mathrm{~s}$ ). There is no change in lick rates versus time at the onset of the adapter stimulus (gray box, left plots, $0 \mathrm{~s}$ ).

The behavioral shifts when preceding the test motion with an adapter are consistent with the motion aftereffect shifts observed in psychometric functions for humans (Blake and Hiris, 1993; Van Wezel and Britten, 2002; Czuba et al., 2011). Furthermore, our analyses of the behavioral changes induced by the adaptor stimuli demonstrate that state changes such as arousal or lick fatigue cannot account for the shifts in behavior we observe (Figs. $6-8)$. The magnitude of the shift in sigmoid functions that we measured in mice is smaller than what has been

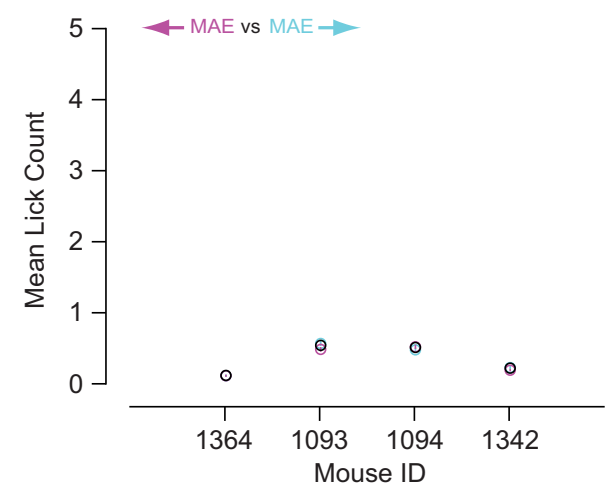

Figure 8. Licking during the adapting phase was infrequent and unrelated to the adapter stimuli. For all four mice, during the adapting phase, average lick rates were $\leq 0.6$ licks/s and were not significantly different between rightward (magenta) and leftward (cyan) adapting conditions $(p>0.05)$. Error bars are SE of the average lick rate and open black circles are the lick counts for the $0 \%$ coherence adapting condition $(n=806-910$ repeats for each condition). observed in humans, but that can be attributed to differences in durations and contrasts for both the adapting and test stimuli. For example, increasing the contrast of the adapter or decreasing the contrast of the test stimulus increase the strength of a motion aftereffect (Keck et al., 1976).

Motion information emerges at multiple stages in the mouse visual system, which may underlie the discrimination behavior we observe. Mice have direction selective cells in their retina (Elstrott et al., 2008; Yonehara et al., 2009; Cruz-Martín et al., 2014; Hillier et al., 2017; Shi et al., 2017), lateral geniculate nucleus (Marshel et al., 2012; Piscopo et al., 2013; Sun et al., 2016), primary visual cortex (Drager, 1975; Niell and Stryker, 2008; Marshel et al., 2011; Rochefort et al., 2011), and the superior colliculus (Drager and Hubel, 1975; Shi et al., 2017). Many questions still remain about the specific circuitry that produces the motion aftereffect. Barlow and Hill (1963) recorded from retinal ganglion cells in the rabbit and discovered that spontaneous activity was reduced following prolonged exposure to the preferred direction of motion, but there was no change to spontaneous activity following prolonged exposure to the opposite direction of motion. This imbalance of activity following the stimulus would lead to a perception of motion in the opposite direction. The direction selective neurons in mouse retina (Elstrott et al., 2008; Yonehara et al., 2009; Cruz-Martín et al., 2014; Hillier et al., 2017; Shi et al., 2017) may adapt in a similar manner. Recent studies also suggest that direction selectivity independently develops in the visual cortex of mice (Hillier et al., 2017; Lien and Scanziani, 
2018; Marques et al., 2018). Similar to the results of Barlow and Hill (1963), experiments in the cat demonstrate that there is reduced activity following the exposure to the preferred direction of motion and no change in activity following the exposure to the opposite direction of motion in cells in the primary visual cortex (Priebe et al., 2010). This simple reduction in activity would not require any special connectivity or organization among direction selective cells and would be a plausible in explaining the motion aftereffect in primates, carnivores, and rodents. Contrast-dependent adaptation properties in the primary visual cortex are similar for mice compared with cats and primates (Ohzawa et al., 1985; Sclar et al., 1989; Bonds, 1991; Crowder et al., 2006, 2008; Kohn, 2007; Stroud et al., 2012).

Recordings in higher areas such as MT in owl monkeys, however, reveal not only a reduction in response following exposure to the preferred direction of motion, but also an enhancement of responses following exposure to the opposite direction of motion, suggesting that competitive circuitry might also contribute to motion processing and the motion aftereffect (Petersen et al., 1985). This was confirmed more recently in area MT of macaque monkeys as well (Kohn and Movshon, 2003). This competition would require specific inhibitory connections between cells with opposing preferred directions of motion or a columnar organization where cells with opposing preferred directions are located next to each other (Malonek et al., 1994; Ohki et al., 2005), which have not been observed in rodents (Ohki et al., 2005). The lack of organization in rodent visual cortex may lead to differences in adaptation properties compared with cats and primates (King and Crowder, 2018), which might be also true for the motion aftereffect.

Recent sensory history is critical to interpreting new incoming sensory information. This is particularly relevant when that incoming information is noisy, uncertain, or ambiguous. The motion aftereffect is an illusion that arises out of the circuitry that helps integrate past and present motion information. Such motion processing is critical to several species, including mice, in stabilizing images while navigating in an environment, avoiding moving objects, or interacting with moving objects and the signatures for this processing appear to be preserved across mammalian species.

\section{References}

Addams R (1834) An account of a peculiar optical phenomenon seen after having looked at a moving body. London Edinburgh Philos Mag J Sci 5:373-374. CrossRef

Anstis S, Verstraten FA, Mather G (1998) The motion aftereffect. Trends Cogn Sci 2:111-117. Medline

Barlow HB, Hill RM (1963) Selective sensitivity to direction of movement in ganglion cells of rabbit retina. Science 139:412-414. Medline

Bischof WF, Reid SL, Wylie DRW, Spetch ML (1999) Perception of coherent motion in random dot displays by pigeons and humans. Percept Psychophys 61:1089-1101. Medline

Blake R, Hiris E (1993) Another means for measuring the motion aftereffect. Vision Res 33:1589-1592. Medline

Bonds AB (1991) Temporal dynamics of contrast gain in single cells of the cat striate cortex. Vis Neurosci 6:239-255. Medline
Brainard DH (1997) The psychophysics toolbox. Spat Vis 10:433436. Medline

Crowder NA, Hietanen MA, Price NSC, Clifford CWG, Ibbotson MR (2008) Dynamic contrast change produces rapid gain control in visual cortex. J Physiol 586:4107-4119. CrossRef Medline

Crowder NA, Price NSC, Hietanen MA, Dreher B, Clifford CWG, lbbotson MR (2006) Relationship between contrast adaptation and orientation tuning in V1 and V2 of cat visual cortex. J Neurophysiol 95:271-283. CrossRef Medline

Cruz-Martín A, El-Danaf RN, Osakada F, Sriram B, Dhande OS, Nguyen PL, Callaway EM, Ghosh A, Huberman AD (2014) A dedicated circuit links direction-selective retinal ganglion cells to the primary visual cortex. Nature 507:358-361. CrossRef Medline

Czuba TB, Rokers B, Guillet K, Huk AC, Cormack LK (2011) Threedimensional motion aftereffects reveal distinct direction-selective mechanisms for binocular processing of motion through depth. $J$ Vis 11(10):18 1-18. CrossRef Medline

Dombeck DA, Khabbaz AN, Collman F, Adelman TL, Tank DW (2007) Imaging large-scale neural activity with cellular resolution in awake, mobile mice. Neuron 56:43-57. CrossRef Medline

Douglas RM, Neve A, Quittenbaum JP, Alam NM, Prusky GT (2006) Perception of visual motion coherence by rats and mice. Vision Res 46:2842-2847. CrossRef Medline

Drager UC (1975) Receptive-fields of single cells and topography in mouse visual-cortex. J Comp Neurol 160:269-290. CrossRef Medline

Drager UC, Hubel DH (1975) Physiology of visual cells in mouse superior colliculus and correlation with somatosensory and auditory input. Nature 253:203-204. Medline

Elstrott J, Anishchenko A, Greschner M, Sher A, Litke AM, Chichilnisky EJ, Feller MB (2008) Direction selectivity in the retina is established independent of visual experience and cholinergic retinal waves. Neuron 58:499-506. CrossRef Medline

Girman SV, Sauvé Y, Lund RD (1999) Receptive field properties of single neurons in rat primary visual cortex. J Neurophysiol 82:301311. CrossRef Medline

Guo ZCV, Hires SA, Li N, O'Connor DH, Komiyama T, Ophir E, Huber D, Bonardi C, Morandell K, Gutnisky D, Peron S, Xu NL, Cox J, Svoboda K (2014) Procedures for behavioral experiments in headfixed mice. Plos One 9:e88678. CrossRef Medline

Hillier D, Fiscella M, Drinnenberg A, Trenholm S, Rompani SB, Raics Z, Katona G, Juettner J, Hierlemann A, Rozsa B, Roska B (2017) Causal evidence for retina-dependent and -independent visual motion computations in mouse cortex. Nat Neurosci 20:960-968. CrossRef Medline

Hubel DH, Wiesel TN (1962) Receptive fields, binocular interaction and functional architecture in cat's visual cortex. J Physiol 160: 106-154. Medline

Hubel DH, Wiesel TN (1968) Receptive fields and functional architecture of monkey striate cortex. J Physiol 195:215-243. Medline

Issa NP, Trepel C, Stryker MP (2000) Spatial frequency maps in cat visual cortex. J Neurosci 20:8504-8514. Medline

Jurjut O, Georgieva P, Busse L, Katzner S (2017) Learning enhances sensory processing in mouse $\mathrm{VI}$ before improving behavior. $\mathrm{J}$ Neurosci 37:6460-6474. CrossRef Medline

Keck MJ, Palella TD, Pantle A (1976) Motion aftereffect as a function of contrast of sinusoidal gratings. Vision Res 16:187-191. Medline

Khastkhodaei Z, Jurjut O, Katzner S, Busse L (2016) Mice can use second-order, contrast-modulated stimuli to guide visual perception. J Neurosci 36:4457-4469. CrossRef Medline

King J, Crowder N (2018) Adaptation to stimulus orientation in mouse primary visual cortex. Eur J Neurosci 47:346-357. CrossRef

Kohn A (2007) Visual adaptation: physiology, mechanisms, and functional benefits. J Neurophysiol 97:3155-3164. CrossRef Medline

Kohn A, Movshon JA (2003) Neuronal adaptation to visual motion in area MT of the macaque. Neuron 39:681-691. Medline

Lien AD, Scanziani M (2018) Cortical direction selectivity emerges at convergence of thalamic synapses. Nature 558:80-86. CrossRef Medline 
Malonek D, Tootell RBH, Grinvald A (1994) Optical imaging reveals the functional architecture of neurons processing shape and motion in owl monkey area MT. Proc Biol Sci 258:109-119. CrossRef

Marques T, Summers MT, Fioreze G, Fridman M, Dias RF, Feller MB, Petreanu $L$ (2018) A role for mouse primary visual cortex in motion perception. Curr Biol 28:1703-1713.e6. CrossRef Medline

Marshel JH, Garrett ME, Nauhaus I, Callaway EM (2011) Functional specialization of seven mouse visual cortical areas. Neuron 72: 1040-1054. CrossRef Medline

Marshel JH, Kaye AP, Nauhaus I, Callaway EM (2012) Anteriorposterior direction opponency in the superficial mouse lateral geniculate nucleus. Neuron 76:713-720. CrossRef Medline

Nauhaus I, Nielsen KJ, Disney AA, Callaway EM (2012) Orthogonal micro-organization of orientation and spatial frequency in primate primary visual cortex. Nat Neurosci 15:1683-1690. CrossRef Medline

Niell CM, Stryker MP (2008) Highly selective receptive fields in mouse visual cortex. J Neurosci 28:7520-7536. CrossRef Medline

Ohki K, Chung S, Ch'ng YH, Kara P, Reid RC (2005) Functional imaging with cellular resolution reveals precise micro-architecture in visual cortex. Nature 433:597-603. CrossRef Medline

Ohzawa I, Sclar G, Freeman RD (1985) Contrast gain-control in the cat's visual-system. J Neurophysiol 54:651-667. CrossRef Medline

Petersen SE, Baker JF, Allman JM (1985) Direction-specific adaptation in area MT of the owl monkey. Brain Res 346:146-150. Medline

Piscopo DM, El-Danaf RN, Huberman AD, Niell CM (2013) Diverse visual features encoded in mouse lateral geniculate nucleus. $J$ Neurosci 33:4642-4656. CrossRef Medline

Priebe NJ, Lampl I, Ferster D (2010) Mechanisms of direction selectivity in cat primary visual cortex as revealed by visual adaptation. J Neurophysiol 104:2615-2623. CrossRef Medline
Rochefort NL, Narushima M, Grienberger C, Marandi N, Hill DN, Konnerth A (2011) Development of direction selectivity in mouse cortical neurons. Neuron 71:425-432. CrossRef Medline

Samonds JM, Geisler WS, Priebe NJ (2018) Natural image and receptive field statistics predict saccade sizes. Nat Neurosci 21: 1591-1599. CrossRef Medline

Schwarz C, Hentschke H, Butovas S, Haiss F, Stüttgen MC, Gerdjikov TV, Bergner CG, Waiblinger C (2010) The head-fixed behaving rat-Procedures and pitfalls. Somatosens Mot Res 27:131-148. CrossRef Medline

Sclar G, Lennie P, Depriest DD (1989) Contrast adaptation in striate cortex of macaque. Vision Res 29:747-755. Medline

Shi XF, Barchini J, Ledesma HA, Koren D, Jin YJ, Liu XR, Wei W, Cang JH (2017) Retinal origin of direction selectivity in the superior colliculus. Nat Neurosci 20:550-558. CrossRef Medline

Stirman JN, Townsend LB, Smith SL (2016) A touchscreen based global motion perception task for mice. Vision Res 127:74-83. CrossRef Medline

Stroud AC, LeDue EE, Crowder NA (2012) Orientation specificity of contrast adaptation in mouse primary visual cortex. J Neurophysiol 108:1381-1391. CrossRef Medline

Sun WZ, Tan ZC, Mensh BD, Ji N (2016) Thalamus provides layer 4 of primary visual cortex with orientation- and direction-tuned inputs. Nat Neurosci 19:308-315. CrossRef Medline

Tabata H, Shimizu N, Wada Y, Miura K, Kawano K (2010) Initiation of the optokinetic response (OKR) in mice. J Vision 10(1):13 1-17. CrossRef Medline

Van Wezel RJA, Britten KH (2002) Motion adaptation in area MT. J Neurophysiol 88:3469-3476. CrossRef Medline

Yonehara K, Ishikane H, Sakuta H, Shintani T, Nakamura-Yonehara K, Kamiji NL, Usui S, Noda M (2009) Identification of retinal ganglion cells and their projections involved in central transmission of information about upward and downward image motion. Plos One 4: e4320. CrossRef Medline 